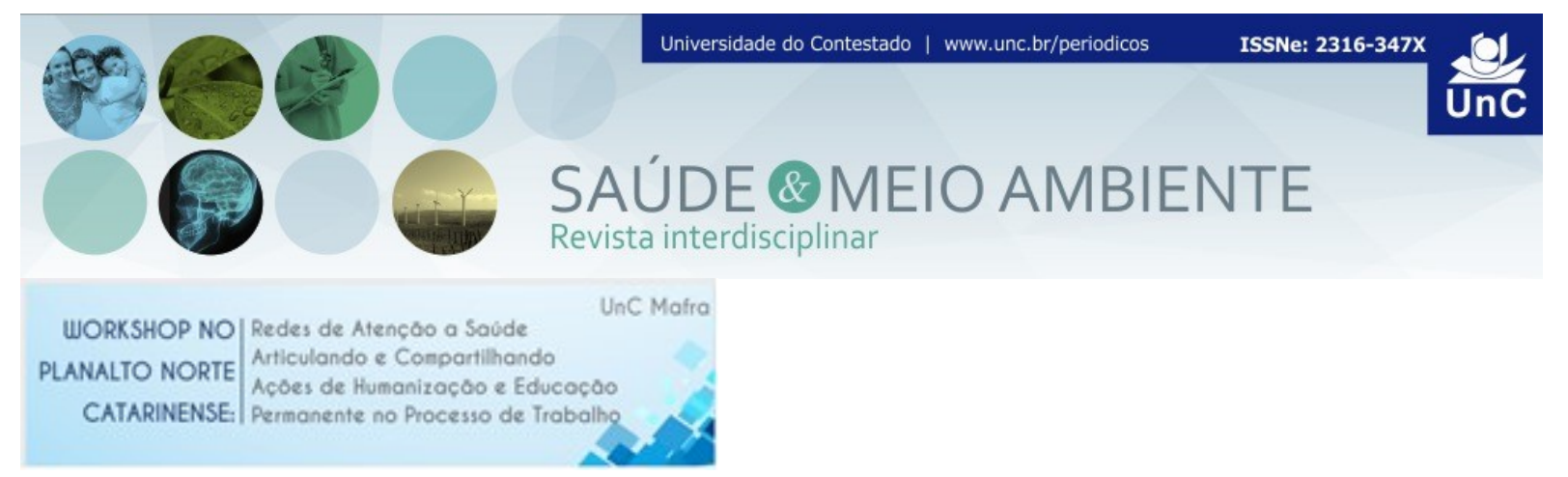

\title{
O USO DAS TECNOLOGIAS LEVES PARA O CUIDADO EM SAÚDE MENTAL
}

Franceli Groskopf ${ }^{1}$

Marina Marquetti ${ }^{2}$

\section{RESUMO}

INTRODUÇÃO: Fazer a diferença na vida das pessoas que necessitam de cuidados em saúde requer mais do que conhecimentos técnicos. Segundo Merhy e Onocko (1997) o trabalho em saúde está pautado no uso de tecnologias classificadas em três categorias: duras, leve-duras e leves. Este trabalho discute o uso das tecnologias leves em saúde mental que se referem às relações estabelecidas por meio da escuta, vínculo, diálogo, acolhimento, autonomia e corresponsabilização, ou seja, envolvem a construção de um processo terapêutico baseado na interação e na confiança entre profissionais e usuários. A importância deste tema está no fato de que as tecnologias leves são a base para o início e fortalecimento das relações entre profissionais e usuários principalmente na atenção primária, fazem parte da rotina de atendimento nos serviços de saúde e consequentemente irão refletir no tratamento. Em razão disso, a discussão desse tema também deveria se tornar rotineira para tornar o uso dessas técnicas cada vez mais aprimoradas. O uso dessas ferramentas contribui para a produção do cuidado humanizado em saúde mental em todos os níveis de atenção. OBJETIVOS: Discutir o uso das tecnologias leves para promover o cuidado em saúde mental. MATERIAL E MÉTODOS: Trata-se de uma revisão bibliográfica, realizada na base de dados do portal de periódicos da CAPES com os termos Saúde Mental e Tecnologias Leves, em artigos escritos em português, com o texto completo disponível e publicados nos últimos dez anos. Realizou-se a leitura dos títulos dos artigos e se atendiam ao propósito da pesquisa, fazia-se a leitura do resumo e posteriormente do artigo. RESULTADOS: As principais ferramentas utilizadas pelos profissionais que atuam em saúde mental não estão vinculadas a equipamentos de alta tecnologia, mas sim com aquilo que depende das pessoas, das relações que os profissionais estão dispostos a estabelecer com os usuários. $O$ processo de cuidado integral envolve a produção de novas perspectivas de intervenção, mais próximas da realidade e das necessidades sociais e individuais dos usuários da rede de saúde. Acolhimento e vínculo são apontados como dispositivos que favorecem o cuidado integral e a autonomia tendo em vista que são construídos a partir do diálogo entre o trabalhador da saúde e o usuário e/ou familiar

\footnotetext{
${ }^{1}$ Terapeuta Ocupacional. Especialista em Saúde Mental e Atenção Psicossocial (Escola de Saúde Pública de Santa Catarina). Mestre em Saúde Coletiva (Universidade Regional de Blumenau FURB). Santa Catarina. Brasil. E-mail: frangroskopf@gmail.com

${ }^{2}$ Assistente Social. Pós-Graduada em Educação Especial Inclusiva (Universidade Cruzeiro do Sul). Prefeitura Municipal de Itaiópolis. Santa Catarina. Brasil. E-mail: ma.marquetti@yahoo.com.br
} 
(JORGE et al., 2011). Algumas pesquisas mostram a necessidade de qualificar o acolhimento, a fim de evitar que este seja feito aos moldes de uma triagem (BARROS et al., 2013; COUTINHO et al., 2015). CONCLUSÕES: As transformações no modelo assistencial em saúde mental levaram a construção de um sistema de saúde psicossocial de base territorial e comunitária que visa atender as demandas sob a perspectiva do cuidado e da atenção integral. Este estudo permitiu refletir como o uso das tecnologias leves no cotidiano das práticas possibilita um trabalho que favorece a autonomia do usuário através de uma participação ativa no processo de tratamento e promoção da saúde.

Palavras-chave: Transtorno mental. Tecnologias Leves. Rede de serviços de saúde.

\section{REFERÊNCIAS}

BARROS, M. M. M.; JORGE, M. S. B; VASCONCELOS, M. G. F. Experiências de famílias com usuários atendidos em dispositivos de atenção psicossocial. Physis., v. 23, n. 3, p. 821-841, 2013. Disponível em <http://dx.doi.org/10.1590/S0103$73312013000300009>$. Acesso em 01 nov. 2017.

COUTINHO, L. R. P; BARBIERI, A. R.; SANTOS, M. L. M. Acolhimento na Atenção Primária à Saúde: revisão integrativa. Saúde debate. v. 39, n. 105, p.514-524, 2015. Disponível em <http://dx.doi.org/10.1590/0103-110420151050002018> Acesso em 02 nov. 2017.

JORGE, M. S. B.; PINTO, D. M.; QUINDERÉ, P. H. D.; PINTO, A. G. A.; SOUSA, F. S. P. S.; CAVALCANTE, C. M. Promoção da Saúde Mental - Tecnologias do Cuidado: vínculo, acolhimento, co-responsabilização e autonomia. Ciênc. saúde coletiva. v. 16, n. 7, p.3051-3060, 2011. Disponível em <http://dx.doi.org/10.1590/S1413-81232011000800005>. Acesso em 02 nov. 2017.

MERHY, E. E.; ONOCKO, R. (Orgs). Agir em saúde: um desafio para o público. São Paulo: Hucitec, 1997.

Resumo recebido em: 11/12/2017

Resumo aprovado em: 17/12/2017

Resumo publicado em: 20/12/2017 